\title{
A GEOGRAFIA FÍSICA: DAS MUTAÇÕES DO MUNDO À NOVA TEIA DO COSMOS
}

\author{
Antonio Carlos Vitte ${ }^{1}$ \\ Artigo recebido em $14 / 10 / 2009$ e aceito em 29/11/2009
}

\begin{abstract}
RESUMO
O presente trabalho examina o processo de reestruturação da geografia física. Organizada a partir da ciência humboldtiana e produto de uma complexa relação entre a naturphilosophie e a ciência newtoniana, a geografia física surgiu para qualificar a natureza e a superfície da Terra, constituindo-se em uma verdadeira metafísica da natureza. O positivismo e posteriormente o impacto da big science no século XX, marcada pela fragmentação epistemológica e com domínio exacerbado da tecnologia, o resultado é a ausência de um corpus teórico, dominando a atomização disciplinar e simbólica das disciplinas da geografia física. Atualmente, há uma profunda contradição entre o conteúdo e a forma das disciplinas da geografia física, que a cada dia mais são incorporadas por outros campos científicos.

Palavras-Chave: Geografia Física; Paradigma; Crise; Campo Científico; Espaço; Natureza.

\section{PHYSICAL GEOGRAPHY: FROM THE WORLD TO CHANGE NEW BAR OF COSMOS}

\begin{abstract}
This paper examines the restructuring process of physical geography. Organized from the science and humboldtiana product of a complex relationship between naturphilosophie and Newtonian science, the physical geography has emerged to describe the nature and the Earth's surface, built into a genuine metaphysics of nature. The positivism and later the impact of big science in the twentieth century, marked by fragmentation and epistemological exacerbated field of technology, the result is the absence of a theoretical corpus, dominating the symbolic and disciplinary fragmentation of the disciplines of physical geography. Currently, there is a profound contradiction between the content and form of the disciplines of physical geography, which are becoming increasingly embedded in other scientific fields.
\end{abstract}

Keywords: Physical Geography; Paradigm; Crisis; Field Scientific, Space, Nature.

\footnotetext{
1 Antonio Carlos Vitte, Departamento de Geografia, Programa de Pós-Graduação em Geografia, Instituto de Geociências, UNICAMP, Campinas (SP), Brasil. CP 6152, CEP 13083-970. E-mail: vitte@ uol.com.br, Pesquisador CNPq.
} 


\section{1 - INTRODUÇÃO}

David Harvey já em 1969 chamava a atenção para a necessidade de desenvolvermos uma filosofia da geografia que, independente do posicionamento político, ideológico ou mesmo metodológico do pesquisador, procurasse conduzir à uma verdadeira essência da geografia e não meramente a uma representação sobre nossa concepção de geografia. Para Harvey (1969, p.29), este esforço seria importante pois identificava, já naquela época, problemas metodológicos muito sérios na geografia, por causa de uma carência de contato com a filosofia, que se refletia, por exemplo, no próprio sentido da descrição geográfica e, em última instância, na explicação de um fato ou fenômeno geográfico. Para o autor, a geografia possuía um forte problema metodológico, resultado de pouca especulação filosófica, com conseqüências na lógica argumentativa e explicativa de seu objeto, o que a tornava vulnerável frente às demais ciências sociais e até mesmo frente às ciências naturais.

Para Ackermann (1963), este problema metodológico seria derivado do fato da geografia não possuir fronteiras epistêmicas muito bem delimitadas, havendo forte confusão entre tema, objeto e disciplina, o que proporcionava por sua vez uma forte confusão na pesquisa, na estrutura lógica dos resultados, além de proporcionar a perda de seu objeto para os demais campos científicos.

Schaefer (1953) por sua vez, argumentou que o problema metodológico da geografia devia-se ao abuso do excepcionalismo, com repercussões negativas frentes às demais ciências, o que acabou por criar a imagem de que a geografia seria uma ciência secundária, sem objeto definido, cabendo-lhe apenas a realização de inventários e descrições desapaixonantes.

Passado quase quatro décadas desses debates que animaram a busca da chamada cientificidade da geografia e que foram revigorados pela chamada revolução teorético-quantitativa, estamos atualmente vivendo um novo dilema, agora em um novo contexto político, econômico, cultural e geográfico, em que a globalização impõem-se no cotidiano das pesssoas, redefinindo lugares, novas relações espaciais e novas escalas espaçotemporais que são construídas e/ou requalificadas. Nesse processo históricosocial, há a criação de um novo sentido de natureza e de suas relações espaçais e temporais, na qual novas dinâmicas "naturais" estão se impondo na superfície da Terra, obrigando-nos a questionar o nosso papel enquanto seres sociais-naturais nesse processo de profundas transformações. É um novo mundo que, de maneira mais trágica do que nos tempos 
das viagens de Magalhães de 1520, como retratada na obra de Umberto Eco, deixamnos perplexos perante os eventos da natureza e a temporalidade e a intensidade com que afetam nossas vidas e nos obrigam a redefinir o sentido da espécie humana na superfície da Terra, exemplificados pelos fenômenos recentes de eventos extremos como enchentes, nevascas, estiagens prolongadas em várias partes do globo.

Mais do que na época do terremoto de Lisboa, ocorrido no dia 2 de novembro de 1755 , curiosamente no dia dos mortos, o tema da catástrofe tenha sido tão forte, tenha atormentado de forma tão significativa o imaginário social e científico da sociedade e da humanidade como agora, lembrando que a sociedade lisboeta naquela época era marcada por forte dogmatismo religioso que a entranhava.

Os iluministas daquela época, como Rousseau, ficaram pasmos e passaram a desacreditar na Ciência Moderna e na tecnologia como caminho para a construção da liberdade, passando a repensar a problemática da relação Homem-Natureza como eixo de reflexão para a reconstrução da vida humana. Atualmente, este problema se apresenta com muito mais força estando envolto e ao mesmo tempo sendo o produto de uma dialética complexa que exige novos padrões explicativos e argumentativos, nos quais a Ciência Moderna e as suas especialidades já não respondem a essa nova demanda.

Parafraseando Walter Benjaminn (1985) se a Ciência Moderna ao retirar a paixão da explicação e da compreensão do mundo, privilegiando o quantitativo, destruiu o Cosmos e impôs à sociedade a rota cartográfica, gerando angustia e melancolia; atualmente, frente às transformações técnicas e tecnológicas que medeiam as relações entre a sociedade e a natureza, estamos vivendo o desespero de Narciso e, ao contrário de Ulisses na Odisséia (MATTOS, 2002), estamos vivendo esse desespero perante a tragédia e a construção de uma fenomenologia do Nada (LIMA, 2005). Agora, as rígidas divisões e sub-divisões disciplinares da Ciência Moderna perderam a razão de ser, onde o sentido de objeto-objetividade, fronteiras, métodos, palavras e coisas (FOUCAULT, 1985) precisam ser revistos e repensados sob novos olhares e novas posturas, pois uma nova teia (CAPRA, 1996) se impõe, como produto de uma transformação ontológica do ser social (LUCKS, 1979).

2. DA QUANTIFICAÇÃO A BIG SCIENCE E O NOVO MODELO DE CIÊNCIA E DE PESQUISA CIENTÍFICA 
Uma mirada sobre a história da Ciência nós podemos perceber que nascimento da Ciência Moderna (ROSSI, 2006) muitas vezes absolutizado apenas como uma revolução cartesiana, não necessariamente se fez por profundas rupturas (KUHN, 1986), mas sim por uma relação complexa e dialética na qual participam a tradição (LIVINGSTONE, 1992) e a necessidade de superação de obstáculos (BACHELARD, 1996). Nesse processo é interessante considerarmos o capital cultural (BOURDIEU, 1992) herdado que ao longo do tempo que vai sendo resignificado e ao mesmo tempo propiciando um avanço nos conceitos e nas categorias internas às epistemologias regionais, obrigando cada campo científico a repensar e transformar-se internamente, ou seja, em sua lógica argumentativa e explicativa. Nesse sentido, os obstáculos constituem-se dialeticamente a partir das relações entre o internalismo e o externalismo.

Tal situação pode ser exemplificada com a questão da validade universal das explicações e do modelo de natureza, duas importantes concepções da Ciência Moderna e que guiarão o princípio da objetividade nas Ciências da Natureza. O trabalho de Kepler, é paradigmático e pode ser situado na fase de transição entre um modelo de ciência com forte conteúdo explicativo advindo da escolástica e às necessidades empíricas e materiais de se criar um novo modelo coerente de natureza. Neste processo esquizofrênico, Kepler (1571-1630) utilizará dos recursos da escolástica, das teorias helenistas sobre a harmonia do mundo, bem como os recursos da astrologia, dentre esses a questão geométrica (CONNOR, 2006).

Dessa forma, a transição foi gradual, na qual colaboraram os gregos com sua filosofia natural, a pesquisa árabe sobre a natureza e a escolástica com sua imagem de mundo. No contexto de transição a concepção mecanicista moderna de natureza emergiu com Laplace (17491827). Nela definitivamente deixou-se de buscar as interrelações gerais dos fenômenos da natureza, para poder alcançar a sua totalidade por meio da pesquisa do particular. Cada vez mais, o analítico e o particular impuseram-se como programa e como necessidade de pesquisa sobre a natureza e seus recursos. É neste momento que a Lei da Gravitação Universal surgirá como novo amálgama do Novo Cosmos que estaria sendo construído pela Ciência Moderna (COHEN e WESTFALL, 1995), um Cosmos a partir de então mecânico e que não admitia possibilidade do Homem enquanto agente.

Cassirer (2001) foi um autor que demonstrou que não necessariamente a matematização do mundo e da natureza provocava a ruptura do mundo da 


\section{RBGF- Revista Brasileira de Geografia Física \\ Recife-PE, Vol.2, n.03, set-dez, 2009, 37-63.}

escolástica para a modernidade. Ao contrário, Nicolau de Cusa (1401-1464), durante o Renascimento, propunha o uso da matemática no entendimento do Cosmos e do sentido do Homem na Terra. A transição veio justamente não pelo método experimental, mas pelo fato de que a crença na transmissão religiosa não explicava e sustentava o sentido de Natureza, do Homem e do Mundo.

Este corte é realizado pelo processo indutivo da pesquisa científica que criou as premissas para o surgimento da nova imagem do mundo. A pressuposição da pesquisa indutiva era, então, que a natureza era regida por leis e que as mesmas causas provocavam os mesmos efeitos. Os resultados favoráveis obtidos com este método de pesquisa a natureza, ou seja, o método residente na observação contínua e nos experimentos com o propósito de descoberta de leis universais induziu à convicção de que o conhecimento só se limitava aquilo que pode ser objeto da percepção sensível.

É graças a esse método experimental-indutivo que as ciências naturais puderam contribuir para $o$ desenvolvimento das revoluções técnicas durante a Revolução Industrial no século XVII. Houve um grande acúmulo de fatos e dados, que serviram para o surgimento da Ciência Moderna e suas especializações que foram gradativamente incorporadas ao modo de produção capitalista. Assim, entre os séculos XIV e XVIII o processo de observação da natureza e a coleta de dados e fatos sobre a mesma propiciou o distanciamento do sentido de Cosmos, com o surgimento de uma concepção de natureza imutável, passível de ser descrita matematicamente e que ao cientista caberia apenas buscar os interrelacionamentos dos fatos por intermédio das leis matemáticas.

Segundo Engels (1820-1895) em sua obra Dialética da Natureza (1991) naquele momento surgiu a concepção de que a natureza é imutável. Ou seja, qualquer que fosse o modo como se formou, esta, uma vez formada, permanecia idêntica a si própria durante o tempo de sua existência. Para Engels (1991) este fato, se de um lado representava um relativo avanço em relação a ciência grega no que diz respeito as técnicas, as coletas de informações, a capacidade de isolar e fragmentar a natureza, por outro lado, mostrava que a própria Ciência Moderna estava em estado inferior, no que dizia respeito ao domínio do pensamento sobre os materiais e a concepção de natureza em geral. Ainda para Engels (op.cit), isso criou uma unilateralidade singular para a história da humanidade, pois na visão mecanicista não havia lugar para Deus e nem para o Homem. Era o fim do Cosmos.

Foi naquele momento que se construiu o conceito de espaço e tempo 
conforme trabalhado por Kant (1982) na Crítica da Razão Pura, que associada à metodologia newtoniana, conforme justificada pelo próprio Kant, expulsará Deus da natureza, abrindo caminho para a construção de superfície a Terra e de mundo, que serão instrumentalizados por sua geografia física (LIVINGSTONE, 1992).

Harvey (2006) argumenta que na medida que o modo de produção capitalista vai se especializando e ao mesmo tempo se espacializando, na medida em que novas configurações espaciais e necessidades sociais vão surgindo, a integração espacial do mundo vai aumentando, exigindo cada vez mais profissionais que lhe expliquem e ao mesmo tempo justifiquem a própria necessidade de integração espacial do capital. É assim que a Geografia nascerá como ciência que procurará desenvolver uma explicação universal sobre a ação do homem na superfície da Terra, e, na medida em que o capital se especializa, a fragmentação não será apenas no plano da espacialidade, com a segregação sócioespacial nas mais variadas escalas, mastambém será cada vez maior a fragmentação do conhecimento geográfico e a relativa independência de determinadas disciplinas, como é o caso daquelas encampadas pela geografia física.

Nesse quadro de extrema especialização que surgiu a big science um produto da modernidade e diferente do processo que resultou na Ciência Moderna, que ao longo do tempo foi sofrendo um impacto do capitalismo cada vez mais oligopólico e atrelado a um complexo industrial-militar, a pesquisa científica será redefinida a partir das necessidades de um novo padrão de organização e consumo do espaço e da natureza em contexto de difusão do modo de produção hegemônico.

Muito embora o termo big science apareça apenas em 1961, formulado por Alvin Weinberg, a mesma vinha sendo constituída durante a II Guerra Mundial (1939-1945), a partir de uma associação entre o complexo industrial-militar norteamericano, os laboratórios de física e astronomia e o governo norte-americano. O maior exemplo dessa associação foi o projeto Manhattan que resultou na bomba atômica de Hiroshima e Nagasaki (WEINBERG, 1961; GALISON e BRUCE, 1992).

Durante a Guerra Fria e principalmente a partir dos anos 1960 as relações ficaram mais estreitas entre $o$ complexo industrial-militar, as políticas de governo e as corporações científicas, com forte impacto nas ciências da vida e nos projetos educacionais, com uma maior racionalização e tecnificação dos currículos, principalmente os de engenharia que acabaram servindo como modelo para as demais áreas científicas. 
A cada dia mais, exigia-se a participação de grupos de pesquisa para a resolução de problemas específicos, o que significou ao longo do tempo a perda da independência de se realizar pesquisa, pois foi crescente a agregação do modelo da big science nos organismos nacionais e internacionais de fomento à pesquisa. Outra conseqüência deste modelo de se fazer ciência foi a exigência da chamada produtividade científica, medida por exemplo em artigos publicados em periódicos de grande impacto internacional e assinado pelo grupo de pesquisa ou por grupos de pesquisadores de diferentes pesquisadores.

O modelo da big science está amplamente adotado por órgãos oficiais de fomento à ciência e a tecnologia e também está altamente entranhado na comunidade científica e na sociedade, a cada dia mais cimentando nossas relações com a pesquisa, a orientações nas graduação e nas pós-graduações com geração de grupos de pesquisa e sendo parâmetro na competição entre os mesmos por reconhecimento e/ou maior participação nas verbas e temas de financiamento. Tal situação leva ao questionamento se não há um paradoxo que leva à uma contradição entre o real e o imaginário-simbólico que estamos construindo sobre uma Nova Ciência.

O quadro conjuntural e estrutural ora apresentado é o de relações sincrônicas cada dia mais intensas entre as ciências, obrigando-nos a repensar sobre a filosofia da ciência e sobre as epistemologias regionais que foram moldadas na modernidade. Mas, não estariam as partes sendo dominantes sobre o todo? Há uma coerência filosófica, existencial e lógica entre o discurso de uma Nova Ciência e a realidade marcada, a cada dia mais, pela segregação sócioespacial em suas múltiplas escalas e temporalidades? Em outras palavras, está sendo construída de fato uma Nova Ciência, um novo padrão cultural e explicativo sobre o mundo, ou se está apenas rearranjando politicamente temas de pesquisa determinados pelo modelo da big science para favorecer determinadas corporações profissionais em prol de temas que assumem o papel de celebridade? Qual o sentido da Nova Ciência? Qual o sentido e o papel da Geografia nesse novo quadro processual?

Muito mais do que apenas um discurso sobre o pragmatismo e a necessidade de formação de profissionais tecnicamente habilitados, a discussão sobre as relações entre a geografia física e as ciências básicas, obrigam-nos a discutir a sua gênese e os fundamentos que lhe estruturaram, posição que necessita ser feita mediante um diálogo constante e profundo com a filosofia

3. A FILOSOFIA-DA-NATUREZA E O SENTIDO DA GEOGRAFIA FÍSICA 


\subsection{Discutindo a Gênese da Geografia}

\section{Física}

Nesta secção pretendemos discutir brevemente o tema ligado ao surgimento da Ciência Moderna, mais particularmente a gênese das Ciências da Natureza, ou seja, como se procedeu a arquitetura do conceito de natureza e como esse conceito foi instrumentalizado e concebido na formação da Ciência Geográfica.

A viabilidade metodológica e científica do estudo sobre a natureza foi construída por Kant (1724-1804), particularmente nas obras Crítica da Razão Pura (CRP), publicada em 1781 (Kant, 1982) e nos Primeiros Princípios Metafísicos da Ciência da Natureza (PPMCN), obra publicada em 1786 (Kant, 1990). O contexto foi de uma revolução copernicana no qual, não somente a razão, mas também o sujeito ganhou estatuto ontológico, havendo também um deslocamento de qualquer interpretação dogmática. Nesse processo de reconstrução do sujeito, seguindo a metodologia newtoniana, a natureza, por sua vez, foi deslocada, em um primeiro momento, como produto da construção da razão, fato que fica melhor exemplificado na CRP, no capítulo da Estética Transcendental, que diz respeito à discussão sobre o espaço e o tempo, assim como na parte relativa à Dedução Transcendental. Já nos Primeiros Princípios Metafísicos da Ciência da
Natureza, Kant sob o impacto da CRP e das críticas que passava a receber por desconsiderar a natureza enquanto objetividade procurou, a partir de então, a justificá-la, assim como a física newtoniana, enquanto método e objeto de estudo independente das vontades da razão. A premissa kantiana nos PPMCN é de que todo o conhecimento é dado pela experiência e, este, não passa de uma ordem de representação dos fenômenos, sendo impossível atribuir-lhe existência independente da realidade. $\mathrm{O}$ conhecimento sobre a natureza é produzido por um jogo entre a intuição e os juízos, que por sua vez fazem a mediação entre as categorias lógico-transcendentais e a experiência.

O resultado dessas reflexões de Kant, particularmente nos PPMCN, foi a validação de uma ciência da natureza, considerada desde que houvesse uma metafísica que lhe sustentasse e uma metodologia que permitisse a mediação entre intuição e juízo. Assim, Kant consagrou a separação entre sujeito e objeto, na qual a causalidade deveria ser reconhecida na totalidade dos fenômenos, ou seja, na natureza. Caberia à Ciência da Natureza investigar o fenômeno natural na perspectiva das condições lógicotranscendentais, portanto universais, enquanto que o particular seria reconhecido somente pelo domínio da 
intuição que agiria sob a jurisdição da razão, ou seja, da universalidade. O problema que se coloca e que redundará no nascimento da Geografia Física Moderna, será aquele relacionado a problemática das particularidades da natureza, e a impossibilidade de explicá-los segundo esquemas do transcendentalismo kantiano, pois os viajantes e naturalistas ao retratarem os diferentes ambientes naturais e suas especificidades acabavam por inviabilizar o princípio do universalismo da razão (VITTE, 2007a).

A resolução de tal problemática resulta em um novo repensar sobre sua própria filosofia e sobre o sentido da natureza na constituição do mundo. $\mathrm{O}$ produto desta reflexão filosófica com uma nova reestruturação de sua metafísica, foi marcado a partir de um novo diálogo com Platão e Leibniz e foi também influenciado pelas revoluções da Biologia, com a constituição do conceito de organismo e de epigenia (VITTE, 2007). Kant produziu a Crítica da Faculdade do Juízo (CJ) em 1790 (KANT, 1995), quando ocorreu uma nova reconceitualização de natureza e espaço. A natureza a partir de então foi entendida enquanto sistema, apresentando uma finalidade (LEBRUN, 2002), sendo mediada por uma nova causalidade e uma nova metafísica. Nelas, a epigenia e a noção de nexus finalis deu um novo sentido de substância, que foi reconceituada como conformidade-a-fins e foi importante para o desenvolvimento do núcleo da Geografia Física, como foi o caso do conceito de geoesfera.

A empiricização desta nova metafísica, em que houve a reconstrução do sentido de substância, ocorreu com o desenvolvimento da Geografia Física, disciplina que o próprio Kant lecionou por quarenta anos (1756 a 1796). Segundo Kuehn (2001, p.83), dos 268 ciclos de cursos universitários ministrados pelo filósofo na universidade de Königsberg, 54 foram dedicados a lógica e metafísica, 49 a geografia física, sendo que estes cursos eram ministrados no mesmo semestre letivo. Consideramos não ser outra razão para esta "aparente" coincidência, senão um motivo filosófico, ou seja, em Kant a Geografia Física é um produto empíricoconceitual-simbólico de uma reflexão filosófica sobre a natureza na superfície da Terra.

Não podemos nunca descolar este rico momento da produção kantiana na formação da geografia física moderna, produto de uma reflexão metafísica sobre a natureza e, conseqüentemente, sobre a superfície da Terra e de seu sistema cosmológico.

Como produto da relação entre suas reflexões filosóficas e do seu curso de Geografia Física, Kant desenvolveu a noção de conformidade-a-fins, conceito 
operacional que permitia ao filósofo conceber a natureza enquanto totalidade e ao mesmo tempo empiricizá-la, na medida em que a concebia como um organismo, portanto de forma estruturada, o que permitia a busca das regularidades $\mathrm{e}$ interconexões sistemáticas (VITTE, 2007a).

O conceito de conformidade-a-fins, que pressupõe uma nova causalidade agora não mais mecânica, foi desenvolvido nos trabalhos de Goethe e Humboldt. Em Goethe (1749-1832) o conceito de conformidade-a-fins será concebido como um princípio plasmador que se realizava, ou seja, tornava-se objetivo, em diferentes morfologias com seus respectivos conteúdos (GOETHE, 1963). Mas foi com a genialidade de Alexander von Humboldt (1764-1859) que a conformidade-a-fins será instrumentalizada e a metafísica da superfície da Terra se realizou efetivamente, na medida em que Humboldt desenvolveu e instrumentaliou-a no conceito de conexões.

Foi nesse momento em que surgiu com destaque a geografia física moderna cujo núcleo é cimentado por uma nova metafísica da substância instrumentalizada pelo conceito de conexões, de onde se desenvolveu os conceitos geográficos de paisagem, geoesfera, processos, morfogênese e tantos outros que garantiram a existência do objeto de pesquisa em geografia física.

\section{2 - A Problemática da Identidade da Geografia Física}

Para Hannah Arendt (2001), a superfície da Terra foi construída pelo homo faber. Nesse processo, a sua justificativa filosófica e metafísica foi possível por meio da Geografia, motivada pelas reflexões kantianas e pelas noções de juízo reflexionante e de conformidade a fins, representadas na Geografia pelas concepções de geoesfera e de paisagem, sendo a paisagem entendida como uma representação da natureza e o produto da relação entre o particular e o universal, cujo fundamento é o belo e o sublime que conjuntamente com a geoesfera, na forma como foi desenvolvida por Alexander Von Humboldt, possuindo um fundamento estético e representam a empiricização e substantivação da conformidade a fins da natureza, aquilo que Goethe chamava de conexões entre os elementos da natureza e que eram dependentes da dinâmica do Cosmos.

O que observamos ao longo do tempo, e principalmente a partir do forte impacto do positivismo na Ciência Geográfica, é que houve uma profunda especialização das disciplinas da geografia física, a ponto de, na maioria das vezes, as 
disciplinas tornarem-se relativamente independentes entre si e principalmente apresentarem-se desconexas em relação ao sentido da Ciência Geográfica e da geografia física em particular. Esse fato se reflete na constante criação de associações independentes, congressos e seminários específicos de cada disciplina e até mesmo de politicamente tentar-se inserir determinadas disciplinas em outros campos de investigação, como pode ser exemplificado pela geomorfologia com a Geologia. A geografia física contemporânea possui uma grande diversidade de assuntos. No entanto, vivemos o problema filosófico da identidade desse campo temático da Ciência Geográfica, frente às novas exigências da sociedade.

Tomando-se a geomorfologia como referência, Rhoads e Thorn (1996) identificaram que há uma forte necessidade de discussões filosóficas sobre a natureza dessa disciplina, que a cada dia mais, está sendo impregnada pela questão cultural e política. Para Gregory $(2000,2001)$ a necessidade de discussão decorre em função do pragmatismo, de forma que não há razão para não refletirmos sobre os conceitos e as práticas da Geografia Física e em particular pela geomorfologia, já que há uma forte incompatibilidade entre a sua formação e a situação atual, quando o ambientalismo está exigindo novas posturas científicas, filosóficas e políticas por parte dos grupos de pesquisa.

Chorley (1971), refletindo sobre a geografia física, já nos anos 70 chamava à atenção para o fato de que devido ao processo de competição entre as ciências naturais e as exatas, a geografia física para não ter o seu núcleo e objeto fragmentado deveria aproximar-se mais da Geografia Humana, uma vez que a superfície da Terra enquanto palco das ações e conflitos entre a sociedade e o ambiente (HAGGETT, 1975) seria um promissor campo para o desenvolvimento deste diálogo, mantendo-se a característica original da Ciência Geográfica e, ao mesmo tempo, colaborando para $\mathrm{o}$ desenvolvimento de ações políticas e públicas frente aos problemas sociais.

Ainda que os levantamentos acima tenham sido feitos em países de herança anglo-saxão, podemos notar que desde Hartshorne (1959) quando discutiu a questão da geografia sistemática não tem ocorrido avanços significativos sob o aspecto metodológico e filosófico. Ainda hoje a geografia física é abordada como um campo que contempla várias disciplinas especializadas, como a geomorfologia, a climatologia, biogeografia (AGNEW e SPENCER, 1999).

Podemos dizer que em função do forte impacto do positivismo na Ciência 
Geográfica, a geografia física acabou sendo composta por diferentes estruturas, muitas delas com padrões epistêmicos e metodológicos contrastantes e desenvolvidos ou agregados sob o rótulo de geografia física, de maneira independente da estrutura genética e formativa da Ciência Geográfica (GOUDIE et al., 1985; GOUDIE, 1986), fato que levou Roads (1999) a dizer que a atualmente a geografia física é uma grande "colcha de retalhos" com várias disciplinas e sérios problemas metodológicos e filosóficos em cada uma delas que permanece uma questão em aberto.

Uma das hipóteses formuladas para esse problema, foi levantado por Thrift e Walling (2000). Para estes autores, enquanto a geografia humana foi fortemente reciclada em suas estruturas filosóficas e metodológicas, propiciando um maior enriquecimento temático e explicativo para a o mundo, a geografia física, por sua vez, permaneceu fechada, vez requerendo cada vez mais inovações técnicas e tecnológicas para o seu desenvolvimento analítico. Isto conduziu à um contato que podemos dizer que foi perigoso com as Ciências Exatas e Naturais, pois levou, assim, à um esfacelamento de seu núcleo e de sua identidade. Os autores acima citam como exemplo dessa situação o fato que é cada vez maior o aumento de artigos vestidos sob a roupagem da geografia física que são publicados por periódicos especializados de disciplinas particulares ou em periódicos multidisciplinares e que o autor contesta se são realmente artigos de geografia física.

Para nós, esse intenso processo de especialização e fragmentação da geografia física, deve-se ao fato de que a cada dia mais estamos nos atrelando a um determinado modelo de ciência, a chamada big science, que cotidianamente povoa nossas mentes e marca nossas concepções de produção efazer Ciência. Nesse contexto fica explícita a fragilidade da Ciência Geográfica, e da geografia física em particular, ao mesmo tempo em que se estabelece um paradoxo, pois há uma supervalorização da climatologia, da geomorfologia, da hidrologia, por exemplo, mas, ao mesmo tempo, há uma forte perda da coesão interna da Ciência Geográfica, de tal forma, que muitos geógrafos tornam-se geólogos, sedimentologistas, pedólogos, paleoclimatologistas, geotecnologistas, cada qual filiando-se a uma associação profissional específica e publicando em periódicos que não necessariamente de Geografia o que por si só não seria um problema, se não houvesse essa crise de identidade a qual estamos nos referindo neste artigo. 
Nicholas Clifford em editoral do Transaction of the Institute of Bristish Geographers (CLIFFORT, 2001) no início deste novo século chamou a atenção para o fato de que um destes impactos da big science na Ciência Geográfica foi o esvaziamento da geografia física nos departamentos de Geografia da Europa, em particular na Inglaterra, onde a constituição dos grupos de pesquisa e dos programas de pesquisa independentes do conjunto do curso de da dinâmica dos departamentos acabou por criar células isoladas que passaram a adquirir a personalidade do pesquisador-chefe, acarretando, com isto, perdas inestimáveis à Ciência Geográfica.

Tem-se então, uma das conseqüências dessa filiação a este programa tecnológico de se produzir Ciência, que é o da big science, e que se reflete na fragmentação da geografia física, como pode ser observada na publicação dos principais periódicos de Geografia em todo o mundo e em especial na Europa. Assim, Gregory, Gurnell e Petts (2002) apresentaram alguns dados que podem ser considerados preocupantes e que refletem esse novo modo de produzir geografia física. Os autores realizaram alguns levantamentos em artigos publicados no Transaction of the Institute of Bristish Geographers, um periódico de impacto internacional no período de 1988 a 1997, fazendo o mesmo nos Annals of the
Association of American e no Australian Geographer, que também são periódicos de impacto internacional. Verificaram que no primeiro periódico, do total de artigos do periódico, apenas $19 \%$ eram de geografia física. No segundo periódico foi de $22 \%$ e no Australian Geographer o percentual de artigos de geografia física foi de $29 \%$. No entanto, para o mesmo período analisado os autores notaram que houve um significativo aumento de artigos relacionados às disciplinas da geografia física em periódicos especializados de outras ciências e em periódicos multidisciplinares.

Um outro aspecto que deve ser observado é que dentre os artigos de disciplinas de geografia física, Gregory, Gunell e Petts (2002) confirmaram as observações de Brown (1975), que a produção de geomorfologia é dominante dentre as demais disciplinas da geografia física.

O predomínio da temática relativa à geomorfologia na geografia física também foi mostrado por Wrigley e Mathews (1986), que realizaram um importante levantamento nos artigos de geografia física em 1984 e verificaram que dos artigos analisados, $25 \%$ foram genericamente classificados como de geomorfologia.

Bodman (2001), por sua vez, pesquisou 30 trabalhos de geografia física. 
$\mathrm{O}$ autor verificou que $50 \%$ dos trabalhos eram de geomorfologia. No periódico Progress in Physical Geography para o período de 1988-97, verificou-se que $38 \%$ do total de artigos eram de geomorfologia e de hidrologia. No entanto, do total dos trabalhos de geomorfologia, $12 \%$ eram de sedimentologia e apenas $6 \%$ tratavam diretamente de relevo. Tal levantamento demonstrou que a geomorfologia stritu sensu está em segundo plano na produção da geografia física já que seu objeto que é o relevo não é contemplado pela maioria dos trabalhos apresentados. Situação mais preocupante relaciona-se a biogeografia, que praticamente estava ausente, naquele período analisado, nas publicações do Progress in Physical Geography. O autor verificou que a maior parte da produção dos artigos de biogeografia estavam concentrados no Ecological Abstracts, que é dominante nos departamentos de biologia e ecologia de diversas universidades.

Segundo Gregory, Gurnell e Petts (2002) é muito significativa a contribuição da Geografia Física em jornais multidisciplinares. Assim, os autores verificaram que na Inglaterra, durante o ano de 1996, tomando a produção de geomorfologia de 21 departamentos, a mesma foi canalizada para periódicos que tratam do quaternário, que segundo os autores, já está se constituindo em um novo campo científico e que provavelmente incorporará as disciplinas da geografia física. No caso da geomorfologia produzida no Brasil e no restante do mundo é que os seus enunciados clássicos assim como suas metodologias e técnicas tradicionais de trabalho em campo vêm sendo questionados por alguns campos das Ciências Naturais, como é o caso da Geologia, que questiona os geomorfologistas a respeito do uso de modelos matemáticos e estatísticos, ao mesmo tempo em que procura redefinir o sentido das atividades de campo e suas técnicas, para que, associado aos modelos matemáticos e a partir de uma nova posição sobre o raciocínio dedutivo, possa desenvolver espacializações sobre, por exemplo, a morfotectônica (BAKER, 1980).

Fica claro, é que há um descompasso entre o processo formador da geografia física, e que permitiu o seu desenvolvimento ao longo dos séculos XIX e XX, e a sua atual situação de fragmentação e de esvaziamento. A situação que se coloca, pois, é de repensar as estratégias de manutenção e de sobrevivência da Geografia Física, não meramente como uma "colcha de retalhos", como vem sendo, sem uma estrutura motivadora de agregação e de construção epistêmica que lhe garanta, de fato, a ação, a objetividade do verbo 
GRAFAR, enquanto espacializar a partir de uma relação entre a totalidade $e$ a particularidade. Situação filosófica e epistêmica que lhe garantiu o status de ciência e que permitiu a construção simbólica não apenas de superfície da Terra, mas principalmente de mundo3.3 -

Pensando as Possibilidades da Reestruturação da Geografia Física

Sem sombra de dúvida alguma, discutir a crise da Geografia e em particular a crise do campo da geografia física é discutir a crise da Ciência Moderna. O que nos coloca, pois sobre quais poderiam ser os caminhos alternativos para a busca de uma reestruturação da geografia física.

A nossa premissa é que não podemos discutir a crise da geografia física independente de discutirmos a Ciência Geográfica. Portanto, nós devemos discutir as relações entre as chamadas geografia física e a geografia humana, situação que não apenas é complexa, tomando como referência a questão dos métodos, das metodologias, dos referenciais; mas que ganha importância e essencialidade se associarmos esta discussão ao papel das geotecnologias na investigação da realidade geográfica (GOODCHILD,1992; KEMP e VCKOVSKI, 1998).

Acreditamos que não é apenas uma questão de discutir o pragmatismo da
Ciência Geográfica e sua inserção nas questões sociais e políticas, para que, com isso, possamos discutir o perfil profissional do geógrafo ou do licenciado em geografia. Mais do que isto, precisamos abrir ao debate a questão da reflexão intelectual sobre o fazer geografia, precisamos rapidamente discutir nossas bases filosóficas e epistemológicas conforme alertou Rhoads e Thorn (1996) para com isto reconstruirmos a geografia física e a Ciência Geográfica.

É preciso assinalar o equívoco de Johnston (1986), quando argumentou que o vocabulário da geografia humana era muito utilizado pelas Ciências Sociais, e que isso dava à geografia humana uma respeitabilidade e condições de existência, enquanto que na geografia física apenas a noção de meio poderia ser aproveitada, pois a tendência seria da "socialização" da natureza e, por isso, seria irrelevante a existência da geografia física como campo da Geografia. Esta concepção e posição ideológica do autor foi alterada radicalmente quando sugeriu que com o aumento das pesquisas multidisciplinares a noção de Geografia, como antes ele concebia, tornou-se obsoleta (JOHNSTON, 1994).

Não devemos esquecer que a Geografia e o campo da geografia física tem uma tradição e que sua gênese está associada à um profundo debate filosófico 
e metafísico sobre a matéria e, conseqüentemente, sobre a natureza e o espaço. Se, portanto, estabelecermos um focus de discussão sobre a geografia física a partir dessa tradição, podemos afirmar que o mesmo está na interação entre a sociedade e o ambiente. Para nós isso significa que este foco é core e deve ser repensado, reestruturado e reposicionado perante à construção de uma Nova Ciência. A situação filosófica e epistemológica que se coloca é a de uma Teia (CAPRA, 1996), em que os nós e os percursos se intercruzam, significando que a cada dia as necessidades de se problematizar e definir um objeto aumenta e passam pelo aspecto relacional e relativo aos outros campos epistêmicos. Isso nos obriga a repensarmos sobre o sentido das fronteiras entre as ciências e o significado do empírico.

Isso não significa que devemos abandonar a tradição, mas que devemos, mais do que nunca, repensarmos eDessa forma, a transição foi gradual, na qual colaboraram os gregos com sua filosofia natural, a pesquisa árabe sobre a natureza e a escolástica com sua imagem de mundo. No contexto de transição a concepção mecanicista moderna de natureza emergiu com Laplace (1749-1827). Nela definitivamente deixou-se de buscar as interrelações gerais dos fenômenos da natureza, para poder alcançar a sua totalidade por meio da pesquisa do particular. Cada vez mais, o analítico e o particular impuseram-se como programa e como necessidade de pesquisa sobre a natureza e seus recursos. É neste momento que a Lei da Gravitação Universal surgirá como novo amálgama do Novo Cosmos que estaria sendo construído pela Ciência Moderna (COHEN e WESTFALL, 1995), um Cosmos a partir de então mecânico e que não admitia possibilidade do Homem enquanto agente.

Cassirer (2001) foi um autor que demonstrou que não necessariamente a matematização do mundo e da natureza provocava a ruptura do mundo da escolástica para a modernidade. Ao contrário, Nicolau de Cusa (1401-1464), durante o Renascimento, propunha o uso da matemática no entendimento do Cosmos e do sentido do Homem na Terra. A transição veio justamente não pelo método experimental, mas pelo fato de que a crença na transmissão religiosa não explicava e sustentava o sentido de Natureza, do Homem e do Mundo.

Este corte é realizado pelo processo indutivo da pesquisa científica que criou as premissas para o surgimento da nova imagem do mundo. A pressuposição da pesquisa indutiva era, então, que a natureza era regida por leis e que as mesmas causas provocavam os mesmos efeitos. Os resultados favoráveis obtidos com este método de pesquisa a natureza, ou seja, o 
método residente na observação contínua e nos experimentos com o propósito de descoberta de leis universais induziu à convicção de que o conhecimento só se limitava aquilo que pode ser objeto da percepção sensível.

É graças a esse método experimental-indutivo que as ciências naturais puderam contribuir para 0 desenvolvimento das revoluções técnicas durante a Revolução Industrial no século XVII. Houve um grande acúmulo de fatos e dados, que serviram para o surgimento da Ciência Moderna e suas especializações que foram gradativamente incorporadas ao modo de produção capitalista. Assim, entre os séculos XIV e XVIII o processo de observação da natureza e a coleta de dados e fatos sobre a mesma propiciou $o$ distanciamento do sentido de Cosmos, com o surgimento de uma concepção de natureza imutável, passível de ser descrita matematicamente e que ao cientista caberia apenas buscar os interrelacionamentos dos fatos por intermédio das leis matemáticas.

Segundo Engels (1820-1895) em sua obra Dialética da Natureza (1991) naquele momento surgiu a concepção de que a natureza é imutável. Ou seja, qualquer que fosse o modo como se formou, esta, uma vez formada, permanecia idêntica a si própria durante o tempo de sua existência. Para Engels (1991) este fato, se de um lado representava um relativo avanço em relação a ciência grega no que diz respeito as técnicas, as coletas de informações, a capacidade de isolar e fragmentar a natureza, por outro lado, mostrava que a própria Ciência Moderna estava em estado inferior, no que dizia respeito ao domínio do pensamento sobre os materiais e a concepção de natureza em geral. Ainda para Engels (op.cit), isso criou uma unilateralidade singular para a história da humanidade, pois na visão mecanicista não havia lugar para Deus e nem para o Homem. Era o fim do Cosmos.

Foi naquele momento que se construiu o conceito de espaço e tempo conforme trabalhado por Kant (1982) na Crítica da Razão Pura, que associada à metodologia newtoniana, conforme justificada pelo próprio Kant, expulsará Deus da natureza, abrindo caminho para a construção de superfície a Terra e de mundo, que serão instrumentalizados por sua geografia física (LIVINGSTONE, 1992).

Harvey (2006) argumenta que na medida que o modo de produção capitalista vai se especializando e ao mesmo tempo se espacializando, na medida em que novas configurações espaciais e necessidades sociais vão surgindo, a integração espacial do mundo vai aumentando, exigindo cada vez mais profissionais que lhe expliquem e ao mesmo tempo justifiquem a própria necessidade de integração espacial do 
capital. É assim que a Geografia nascerá como ciência que procurará desenvolver uma explicação universal sobre a ação do homem na superfície da Terra, e, na medida em que o capital se especializa, a fragmentação não será apenas no plano da espacialidade, com a segregação sócioespacial nas mais variadas escalas, mas também será cada vez maior a fragmentação do conhecimento geográfico e a relativa independência de determinadas disciplinas, como é o caso daquelas encampadas pela geografia física.

Nesse quadro de extrema especialização que surgiu a big science um produto da modernidade e diferente do processo que resultou na Ciência Moderna, que ao longo do tempo foi sofrendo um impacto do capitalismo cada vez mais oligopólico e atrelado a um complexo industrial-militar, a pesquisa científica será redefinida a partir das necessidades de um novo padrão de organização e consumo do espaço e da natureza em contexto de difusão do modo de produção hegemônico.

Muito embora o termo big science apareça apenas em 1961, formulado por Alvin Weinberg, a mesma vinha sendo constituída durante a II Guerra Mundial (1939-1945), a partir de uma associação entre o complexo industrial-militar norteamericano, os laboratórios de física e astronomia e o governo norte-americano. O maior exemplo dessa associação foi o projeto Manhattan que resultou na bomba atômica de Hiroshima e Nagasaki (WEINBERG, 1961; GALISON e BRUCE, 1992).

Durante a Guerra Fria e principalmente a partir dos anos 1960 as relações ficaram mais estreitas entre $o$ complexo industrial-militar, as políticas de governo e as corporações científicas, com forte impacto nas ciências da vida e nos projetos educacionais, com uma maior racionalização e tecnificação dos currículos, principalmente os de engenharia que acabaram servindo como modelo para as demais áreas científicas.

A cada dia mais, exigia-se a participação de grupos de pesquisa para a resolução de problemas específicos, o que significou ao longo do tempo a perda da independência de se realizar pesquisa, pois foi crescente a agregação do modelo da big science nos organismos nacionais $\mathrm{e}$ internacionais de fomento à pesquisa. Outra conseqüência deste modelo de se fazer ciência foi a exigência da chamada produtividade científica, medida por exemplo em artigos publicados em periódicos de grande impacto internacional e assinado pelo grupo de pesquisa ou por grupos de pesquisadores de diferentes pesquisadores.

O modelo da big science está amplamente adotado por órgãos oficiais de fomento à ciência e a tecnologia e 
tambémestá altamente entranhado na comunidade científica e na sociedade, a cada dia mais cimentando nossas relações com a pesquisa, a orientações nas graduação e nas pós-graduações com geração de grupos de pesquisa e sendo parâmetro na competição entre os mesmos por reconhecimento e/ou maior participação nas verbas e temas de financiamento. Tal situação leva ao questionamento se não há um paradoxo que leva à uma contradição entre o real e o imaginário-simbólico que estamos construindo sobre uma Nova Ciência.

O quadro conjuntural e estrutural ora apresentado é o de relações sincrônicas cada dia mais intensas entre as ciências, obrigando-nos a repensar sobre a filosofia da ciência e sobre as epistemologias regionais que foram moldadas na modernidade. Mas, não estariam as partes sendo dominantes sobre o todo? Há uma coerência filosófica, existencial e lógica entre o discurso de uma Nova Ciência e a realidade marcada, a cada dia mais, pela segregação sócioespacial em suas múltiplas escalas e temporalidades? Em outras palavras, está sendo construída de fato uma Nova Ciência, um novo padrão cultural e explicativo sobre o mundo, ou se está apenas rearranjando politicamente temas de pesquisa determinados pelo modelo da big science para favorecer determinadas corporações profissionais em prol de temas que assumem o papel de celebridade? Qual o sentido da Nova Ciência? Qual o sentido e o papel da Geografia nesse novo quadro processual? Muito mais do que apenas um discurso sobre o pragmatismo e a necessidade de formação de profissionais tecnicamente habilitados, a discussão sobre as relações entre a geografia física e as ciências básicas, obrigam-nos a discutir a sua gênese e os fundamentos que lhe estruturaram, posição que necessita ser feita mediante um diálogo constante e profundo com a filosofia.

\section{A FILOSOFIA-DA-NATUREZA E O SENTIDO DA GEOGRAFIA FÍSICA}

\subsection{Discutindo a Gênese da Geografia}

\section{Física}

Nesta secção pretendemos discutir brevemente o tema ligado ao surgimento da Ciência Moderna, mais particularmente a gênese das Ciências da Natureza, ou seja, como se procedeu a arquitetura do conceito de natureza e como esse conceito foi instrumentalizado e concebido na formação da Ciência Geográfica.

A viabilidade metodológica e científica do estudo sobre a natureza foi construída por Kant (1724-1804), particularmente nas obras Crítica da Razão Pura (CRP), publicada em 1781 (Kant, 1982) e nos Primeiros Princípios Metafísicos da Ciência da Natureza 
(PPMCN), obra publicada em 1786 (Kant, 1990). O contexto foi de uma revolução copernicana no qual, não somente a razão, mas também o sujeito ganhou estatuto ontológico, havendo também um deslocamento de qualquer interpretação dogmática. Nesse processo de reconstrução do sujeito, seguindo a metodologia newtoniana, a natureza, por sua vez, foi deslocada, em um primeiro momento, como produto da construção da razão, fato que fica melhor exemplificado na CRP, no capítulo da Estética Transcendental, que diz respeito à discussão sobre o espaço e o tempo, assim como na parte relativa à Dedução Transcendental. Já nos Primeiros Princípios Metafísicos da Ciência da Natureza, Kant sob o impacto da CRP e das críticas que passava a receber por desconsiderar a natureza enquanto objetividade procurou, a partir de então, a justificá-la, assim como a física newtoniana, enquanto método e objeto de estudo independente das vontades da razão. A premissa kantiana nos PPMCN é de que todo o conhecimento é dado pela experiência e, este, não passa de uma ordem de representação dos fenômenos, sendo impossível atribuir-lhe existência independente da realidade. $\mathrm{O}$ conhecimento sobre a natureza é produzido por um jogo entre a intuição e os juízos, que por sua vez fazem a mediação entre as categorias lógico-transcendentais e a experiência.

O resultado dessas reflexões de Kant, particularmente nos PPMCN, foi a validação de uma ciência da natureza, considerada desde que houvesse uma metafísica que lhe sustentasse e uma metodologia que permitisse a mediação entre intuição e juízo. Assim, Kant consagrou a separação entre sujeito e objeto, na qual a causalidade deveria ser reconhecida na totalidade dos fenômenos, ou seja, na natureza. Caberia à Ciência da Natureza investigar o fenômeno natural na perspectiva das condições lógicotranscendentais, portanto universais, enquanto que o particular seria reconhecido somente pelo domínio da intuição que agiria sob a jurisdição da razão, ou seja, da universalidade.

O problema que se coloca e que redundará no nascimento da Geografia Física Moderna, será aquele relacionado a problemática das particularidades da natureza, e a impossibilidade de explicálos segundo esquemas do transcendentalismo kantiano, pois os viajantes e naturalistas ao retratarem os diferentes ambientes naturais e suas especificidades acabavam por inviabilizar o princípio do universalismo da razão (VITTE, 2007a).

A resolução de tal problemática resulta em um novo repensar sobre sua 
própria filosofia e sobre o sentido da natureza na constituição do mundo. $\mathrm{O}$ produto desta reflexão filosófica com uma nova reestruturação de sua metafísica, foi marcado a partir de um novo diálogo com Platão e Leibniz e foi também influenciado pelas revoluções da Biologia, com a constituição do conceito de organismo e de epigenia (VITTE, 2007). Kant produziu a Crítica da Faculdade do Juízo (CJ) em 1790 (KANT, 1995), quando ocorreu uma nova reconceitualização de natureza e espaço. A natureza a partir de então foi entendida enquanto sistema, apresentando uma finalidade (LEBRUN, 2002), sendo mediada por uma nova causalidade e uma nova metafísica. Nelas, a epigenia e a noção de nexus finalis deu um novo sentido de substância, que foi reconceituada como conformidade-a-fins e foi importante para o desenvolvimento do núcleo da Geografia Física, como foi o caso do conceito de geoesfera.

A empiricização desta nova metafísica, em que houve a reconstrução do sentido de substância, ocorreu com o desenvolvimento da Geografia Física, disciplina que o próprio Kant lecionou por quarenta anos (1756 a 1796). Segundo Kuehn (2001, p.83), dos 268 ciclos de cursos universitários ministrados pelo filósofo na universidade de Königsberg, 54 foram dedicados a lógica e metafísica, 49 a geografia física, sendo que estes cursos eram ministrados no mesmo semestre letivo. Consideramos não ser outra razão para esta "aparente" coincidência, senão um motivo filosófico, ou seja, em Kant a Geografia Física é um produto empíricoconceitual-simbólico de uma reflexão filosófica sobre a natureza na superfície da Terra.

Não podemos nunca descolar este rico momento da produção kantiana na formação da geografia física moderna, produto de uma reflexão metafísica sobre a natureza e, conseqüentemente, sobre a superfície da Terra e de seu sistema cosmológico.

Como produto da relação entre suas reflexões filosóficas e do seu curso de Geografia Física, Kant desenvolveu a noção de conformidade-a-fins, conceito operacional que permitia ao filósofo conceber a natureza enquanto totalidade e ao mesmo tempo empiricizá-la, na medida em que a concebia como um organismo, portanto de forma estruturada, o que permitia a busca das regularidades e interconexões sistemáticas (VITTE, 2007a).

$\mathrm{O}$ conceito de conformidade-a-fins, que pressupõe uma nova causalidade agora não mais mecânica, foi desenvolvido nos trabalhos de Goethe e Humboldt. Em Goethe (1749-1832) o conceito de conformidade-a-fins será concebido como um princípio plasmador que se realizava, 
ou seja, tornava-se objetivo, em diferentes morfologias com seus respectivos conteúdos (GOETHE, 1963). Mas foi com a genialidade de Alexander von Humboldt (1764-1859) que a conformidade-a-fins será instrumentalizada e a metafísica da superfície da Terra se realizou efetivamente, na medida em que Humboldt desenvolveu e instrumentaliou-a no conceito de conexões.

Foi nesse momento em que surgiu com destaque a geografia física moderna cujo núcleo é cimentado por uma nova metafísica da substância instrumentalizada pelo conceito de conexões, de onde se desenvolveu os conceitos geográficos de paisagem, geoesfera, processos, morfogênese e tantos outros que garantiram a existência do objeto de pesquisa em geografia física.

\section{2 - A Problemática da Identidade da Geografia Física}

Para Hannah Arendt (2001), a superfície da Terra foi construída pelo homo faber. Nesse processo, a sua justificativa filosófica e metafísica foi possível por meio da Geografia, motivada pelas reflexões kantianas e pelas noções de juízo reflexionante e de conformidade a fins, representadas na Geografia pelas concepções de geoesfera e de paisagem, sendo a paisagem entendida como uma representação da natureza e o produto da relação entre o particular e o universal, cujo fundamento é o belo e o sublime que conjuntamente com a geoesfera, na forma como foi desenvolvida por Alexander Von Humboldt, possuindo um fundamento estético e representam a empiricização e substantivação da conformidade a fins da natureza, aquilo que Goethe chamava de conexões entre os elementos da natureza e que eram dependentes da dinâmica do Cosmos.

O que observamos ao longo do tempo, e principalmente a partir do forte impacto do positivismo na Ciência Geográfica, é que houve uma profunda especialização das disciplinas da geografia física, a ponto de, na maioria das vezes, as disciplinas tornarem-se relativamente independentes entre si e principalmente apresentarem-se desconexas em relação ao sentido da Ciência Geográfica e da geografia física em particular. Esse fato se reflete na constante criação de associações independentes, congressos e seminários específicos de cada disciplina e até mesmo de politicamente tentar-se inserir determinadas disciplinas em outros campos de investigação, como pode ser exemplificado pela geomorfologia com a Geologia. A geografia física contemporânea possui uma grande diversidade de assuntos. No entanto, vivemos o problema filosófico da 
identidade desse campo temático da Ciência Geográfica, frente às novas exigências da sociedade.

Tomando-se a geomorfologia como referência, Rhoads e Thorn (1996) identificaram que há uma forte necessidade de discussões filosóficas sobre a natureza dessa disciplina, que a cada dia mais, está sendo impregnada pela questão cultural e política. Para Gregory (2000, 2001) a necessidade de discussão decorre em função do pragmatismo, de forma que não há razão para não refletirmos sobre os conceitos e as práticas da Geografia Física e em particular pela geomorfologia, já que há uma forte incompatibilidade entre a sua formação e a situação atual, quando o ambientalismo está exigindo novas posturas científicas, filosóficas e políticas por parte dos grupos de pesquisa.

Chorley (1971), refletindo sobre a geografia física, já nos anos 70 chamava à atenção para o fato de que devido ao processo de competição entre as ciências naturais e as exatas, a geografia física para não ter o seu núcleo e objeto fragmentado deveria aproximar-se mais da Geografia Humana, uma vez que a superfície da Terra enquanto palco das ações e conflitos entre a sociedade e o ambiente (HAGGETT, 1975) seria um promissor campo para o desenvolvimento deste diálogo, mantendo-se a característica original da Ciência Geográfica e, ao mesmo tempo, colaborando para o desenvolvimento de ações políticas e públicas frente aos problemas sociais.

Ainda que os levantamentos acima tenham sido feitos em países de herança anglo-saxão, podemos notar que desde Hartshorne (1959) quando discutiu a questão da geografia sistemática não tem ocorrido avanços significativos sob $\mathrm{o}$ aspecto metodológico e filosófico. Ainda hoje a geografia física é abordada como um campo que contempla várias disciplinas especializadas, como a geomorfologia, a climatologia, biogeografia (AGNEW e SPENCER, 1999).

Podemos dizer que em função do forte impacto do positivismo na Ciência Geográfica, a geografia física acabou sendo composta por diferentes estruturas, muitas delas com padrões epistêmicos e metodológicos contrastantes e desenvolvidos ou agregados sob o rótulo de geografia física, de maneira independente da estrutura genética e formativa da Ciência Geográfica (GOUDIE et al., 1985; GOUDIE, 1986), fato que levou Roads (1999) a dizer que a atualmente a geografia física é uma grande "colcha de retalhos" com várias disciplinas e sérios problemas metodológicos e filosóficos em cada uma delas que permanece uma questão em aberto. 
Uma das hipóteses formuladas para esse problema, foi levantado por Thrift e Walling (2000). Para estes autores, enquanto a geografia humana foi fortemente reciclada em suas estruturas filosóficas e metodológicas, propiciando um maior enriquecimento temático e explicativo para a o mundo, a geografia física, por sua vez, permaneceu fechada, vez requerendo cada vez mais inovações técnicas e tecnológicas para o seu desenvolvimento analítico. Isto conduziu à um contato que podemos dizer que foi perigoso com as Ciências Exatas e Naturais, pois levou, assim, à um esfacelamento de seu núcleo e de sua identidade. Os autores acima citam como exemplo dessa situação o fato que é cada vez maior o aumento de artigos vestidos sob a roupagem da geografia física que são publicados por periódicos especializados de disciplinas particulares ou em periódicos multidisciplinares e que o autor contesta se são realmente artigos de geografia física.

Para nós, esse intenso processo de especialização e fragmentação da geografia física, deve-se ao fato de que a cada dia mais estamos nos atrelando a um determinado modelo de ciência, a chamada big science, que cotidianamente povoa nossas mentes e marca nossas concepções de produção e fazer Ciência. Nesse contexto fica explícita a fragilidade da
Ciência Geográfica, e da geografia física em particular, ao mesmo tempo em que se estabelece um paradoxo, pois há uma supervalorização da climatologia, da geomorfologia, da hidrologia, por exemplo, mas, ao mesmo tempo, há uma forte perda da coesão interna da Ciência Geográfica, de tal forma, que muitos geógrafos tornam-se geólogos, sedimentologistas, pedólogos, paleoclimatologistas, geotecnologistas, cada qual filiando-se a uma associação profissional específica e publicando em periódicos que não necessariamente de Geografia o que por si só não seria um problema, se não houvesse essa crise de identidade a qual estamos nos referindo neste artigo.

Nicholas Clifford em editoral do Transaction of the Institute of Bristish Geographers (CLIFFORT, 2001) no início deste novo século chamou a atenção para o fato de que um destes impactos da big science na Ciência Geográfica foi o esvaziamento da geografia física nos departamentos de Geografia da Europa, em particular na Inglaterra, onde a constituição dos grupos de pesquisa e dos programas de pesquisa independentes do conjunto do curso de da dinâmica dos departamentos acabou por criar células isoladas que passaram a adquirir a personalidade do pesquisador-chefe, acarretando, com isto, perdas inestimáveis à Ciência Geográfica. 


\section{RBGF- Revista Brasileira de Geografia Física \\ Recife-PE, Vol.2, n.03, set-dez, 2009, 37-63.}

Tem-se então, uma das consequiências dessa filiação a este programa tecnológico de se produzir Ciência, que é o da big science, e que se reflete na fragmentação da geografia física, como pode ser observada na publicação dos principais periódicos de Geografia em todo o mundo e em especial na Europa. Assim, Gregory, Gurnell e Petts (2002) apresentaram alguns dados que podem ser considerados preocupantes e que refletem esse novo modo de produzir geografia física. Os autores realizaram alguns levantamentos em artigos publicados no Transaction of the Institute of Bristish Geographers, um periódico de impacto internacional no período de 1988 a 1997, fazendo o mesmo nos Annals of the Association of American e no Australian Geographer, que também são periódicos de impacto internacional. Verificaram que no primeiro periódico, do total de artigos do periódico, apenas $19 \%$ eram de geografia física. No segundo periódico foi de $22 \%$ e no Australian Geographer o percentual de artigos de geografia física foi de $29 \%$. No entanto, para o mesmo período analisado os autores notaram que houve um significativo aumento de artigos relacionados às disciplinas da geografia física em periódicos especializados de outras ciências e em periódicos multidisciplinares.
Um outro aspecto que deve ser observado é que dentre os artigos de disciplinas de geografia física, Gregory, Gunell e Petts (2002) confirmaram as observações de Brown (1975), que a produção de geomorfologia é dominante dentre as demais disciplinas da geografia física.

O predomínio da temática relativa à geomorfologia na geografia física também foi mostrado por Wrigley e Mathews (1986), que realizaram um importante levantamento nos artigos de geografia física em 1984 e verificaram que dos artigos analisados, $25 \%$ foram genericamente classificados como de geomorfologia.

Bodman (2001), por sua vez, pesquisou 30 trabalhos de geografia física. $\mathrm{O}$ autor verificou que $50 \%$ dos trabalhos eram de geomorfologia. No periódico Progress in Physical Geography para o período de 1988-97, verificou-se que $38 \%$ do total de artigos eram de geomorfologia e de hidrologia. No entanto, do total dos trabalhos de geomorfologia, $12 \%$ eram de sedimentologia e apenas $6 \%$ tratavam diretamente de relevo. Tal levantamento demonstrou que a geomorfologia stritu sensu está em segundo plano na produção da geografia física já que seu objeto que é o relevo não é contemplado pela maioria dos trabalhos apresentados. Situação mais preocupante relaciona-se a biogeografia, 
que praticamente estava ausente, naquele período analisado, nas publicações do Progress in Physical Geography. O autor verificou que a maior parte da produção dos artigos de biogeografia estavam concentrados no Ecological Abstracts, que é dominante nos departamentos de biologia e ecologia de diversas universidades.

Segundo Gregory, Gurnell e Petts (2002) é muito significativa a contribuição da Geografia Física em jornais multidisciplinares. Assim, os autores verificaram que na Inglaterra, durante o ano de 1996, tomando a produção de geomorfologia de 21 departamentos, a mesma foi canalizada para periódicos que tratam do quaternário, que segundo os autores, já está se constituindo em um novo campo científico e que provavelmente incorporará as disciplinas da geografia física.

No caso da geomorfologia produzida no Brasil e no restante do mundo é que os seus enunciados clássicos assim como suas metodologias e técnicas tradicionais de trabalho em campo vêm sendo questionados por alguns campos das Ciências Naturais, como é o caso da Geologia, que questiona os geomorfologistas a respeito do uso de modelos matemáticos e estatísticos, ao mesmo tempo em que procura redefinir o sentido das atividades de campo e suas técnicas, para que, associado aos modelos matemáticos e a partir de uma nova posição sobre o raciocínio dedutivo, possa desenvolver espacializações sobre, por exemplo, a morfotectônica (BAKER, 1980).

Fica claro, é que há um descompasso entre o processo formador da geografia física, e que permitiu o seu desenvolvimento ao longo dos séculos XIX e XX, e a sua atual situação de fragmentação e de esvaziamento. A situação que se coloca, pois, é de repensar as estratégias de manutenção e de sobrevivência da Geografia Física, não meramente como uma "colcha de retalhos", como vem sendo, sem uma estrutura motivadora de agregação e de construção epistêmica que lhe garanta, de fato, a ação, a objetividade do verbo GRAFAR, enquanto espacializar a partir de uma relação entre a totalidade e a particularidade. Situação filosófica e epistêmica que lhe garantiu o status de ciência e que permitiu a construção simbólica não apenas de superfície da Terra, mas principalmente de mundo.

\section{3 - Pensando as Possibilidades da Reestruturação da Geografia Física}

Sem sombra de dúvida alguma, discutir a crise da Geografia e em particular a crise do campo da geografia física é discutir a crise da Ciência 
Moderna. O que nos coloca, pois sobre quais poderiam ser os caminhos alternativos para a busca de uma reestruturação da geografia física.

A nossa premissa é que não podemos discutir a crise da geografia física independente de discutirmos a Ciência Geográfica. Portanto, nós devemos discutir as relações entre as chamadas geografia física e a geografia humana, situação que não apenas é complexa, tomando como referência a questão dos métodos, das metodologias, dos referenciais; mas que ganha importância e essencialidade se associarmos esta discussão ao papel das geotecnologias na investigação da realidade geográfica (GOODCHILD,1992; KEMP e VCKOVSKI, 1998).

Acreditamos que não é apenas uma questão de discutir o pragmatismo da Ciência Geográfica e sua inserção nas questões sociais e políticas, para que, com isso, possamos discutir o perfil profissional do geógrafo ou do licenciado em geografia. Mais do que isto, precisamos abrir ao debate a questão da reflexão intelectual sobre o fazer geografia, precisamos rapidamente discutir nossas bases filosóficas e epistemológicas conforme alertou Rhoads e Thorn (1996) para com isto reconstruirmos a geografia física e a Ciência Geográfica.

É preciso assinalar o equívoco de Johnston (1986), quando argumentou que o vocabulário da geografia humana era muito utilizado pelas Ciências Sociais, e que isso dava à geografia humana uma respeitabilidade e condições de existência, enquanto que na geografia física apenas a noção de meio poderia ser aproveitada, pois a tendência seria da "socialização" da natureza e, por isso, seria irrelevante a existência da geografia física como campo da Geografia. Esta concepção e posição ideológica do autor foi alterada radicalmente quando sugeriu que com o aumento das pesquisas multidisciplinares a noção de Geografia, como antes ele concebia, tornou-se obsoleta (JOHNSTON, 1994).

Não devemos esquecer que a Geografia e o campo da geografia física tem uma tradição e que sua gênese está associada à um profundo debate filosófico e metafísico sobre a matéria e, conseqüentemente, sobre a natureza e o espaço. Se, portanto, estabelecermos um focus de discussão sobre a geografia física a partir dessa tradição, podemos afirmar que o mesmo está na interação entre a sociedade e o ambiente. Para nós isso significa que este foco é core e deve ser repensado, reestruturado e reposicionado perante à construção de uma Nova Ciência. A situação filosófica e epistemológica que se coloca é a de uma Teia (CAPRA, 1996), em que os nós e os percursos se intercruzam, significando que a cada dia as 
necessidades de se problematizar e definir um objeto aumenta e passam pelo aspecto relacional e relativo aos outros campos epistêmicos. Isso nos obriga a repensarmos sobre o sentido das fronteiras entre as ciências e o significado do empírico.

Isso não significa que devemos abandonar a tradição, mas que devemos, mais do que nunca, repensarmos e refletirmos sobre as epistemologias envolvidas na explicação geográfica (RHOADS, 1999), considerando que o core da Geografia Física sempre foi composto por disciplinas diversas, multiplas e com vários graus de pluralismo (GOUDIE, 1986; LIVINGSTONE, 2000).

A magnitude do impacto humano sobre o ambiente e a necessidade de predizer as mudanças para o futuro em face do crescimento da população mundial e do uso dos recursos naturais e energéticos demandam um novo papel para a Ciência Geográfica com o problema da análise ambiental em contexto de sustentabilidade o que acirra a insustentabilidade do modo de produção capitalista. Esse novo papel requer uma ação integrada dentro da geografia física; um diálogo que transcenda às fronteiras tradicionais e leve à um rejuvenescimento da Geografia como um todo. Significa dizer que a Ciência Geográfica deve ter uma nova postura frente as transformações do mundo, com um repensar sobre a experimentação, a própria representação do espaço e a comunicabilidade científica.

Por outro lado, não devemos nos enganar. A questão não é de pragmatismo ou de usos e abusos de tecnologias e de geotecnologias. $\mathrm{O}$ problema central, mesmo o que é colocado pela questão ambiental para a geografia física é de ontologia (HARVEY, 1996). Há, eminentemente, um problema filosófico que afeta a Ciência Geográfica e sua postura sobre um mundo em transformação e que exige imediatamente um repensar sobre o sentido de sociedade e de natureza na atual fase contemporânea.

Efetivamente é o momento de reconstruirmos uma nova metafísica da superfície da Terra e um novo sentido de mundo. Para tanto, nós devemos repensar nossas bases e o sentido de unidade para uma Nova Ciência Geográfica e uma nova concepção de natureza no imaginário humano.

Refletindo sobre esta nova empreitada, a qual seja, a de reconstruir o sentido de mundo e da natureza e sua geograficidade, não podemos realizar este trabalho sem repensarmos e buscarmos os elos de interconectividade e a interdefinibilidade (CASANOVA, 2006) interna a Ciência Geográfica e a que definiu o core da geografia física.

Doreen Massey $(1999 ; 2007)$ afirma que esta construção pode estar na 
interconectividade (CASANOVA, 2006) entre e espaço e tempo. As transformações acarretadas na ciência em geral pela teoria da relatividade e pelo posterior desenvolvimento da mecânica quântica forçam à Ciência Geográfica a repensar-se e a questionar a sua postura frente às concepções de espaço e de tempo. Esse repensar coloca à Ciência Geográfica e, portanto, aos campos da geografia humana e da geografia física a dialogarem sobre as suas interpretações e posturas sobre o espaço e o tempo. Esta discussão, segundo Massey (1999; 2007) passa, necessariamente por uma postura filosófica, que exige uma postura ontológica no debate geográfico, conduzindo, com isto, a construção da identidade na Geografia, muito embora a diferença seja um elemento importante, já que espaço e tempo são relacionais.

Espaço e tempo não podem ser concebidos como que categorias separadas, mas como entidades em processo, processo relacionado à própria teia do Cosmos, que se manifesta como coexistente, portanto relativo e relacional, como inclusive já havia refletido Leibniz (GUEROULT, 1967; HARVEY, 1996). Por isso, devemos refletir em termos de espaço-tempo, uma unidade, em que a Ciência Geográfica e o campo da geografia física em particular, representam a possibilidade de espacialização e de construção desta representação, definida a partir de um novo sentido de causalidade, não mais linear, mas que ocorre em rede. Nesse quadro que emerge a possibilidade de reconstrução da geografia física, não mais como "colcha" ou apenas um agregado de disciplinas isoladas, mas como campo integrado $\mathrm{e}$ integrador da reflexão sobre o mundo.

Deve-se construir e buscar e repensar sobre novas bases, a partir de um conceito cimentante, produto dessa reflexão que diz diretamente respeito ao campo epistemológico articulador deste novo coexistente e das novas interconectividades na tessitura do Cosmos que se ligarão ou se re-ligarão ao permanente novo mundo em construção, pois há uma co-produtividade do mundo e da natureza. Se não é por outra razão filosófica e ontológica que a Geografia, produto de uma reflexão filosófica justificou a construção do sentido de mundo às nossas vidas.

\section{REFERÊNCIAS BIBLIOGRÁFICAS} ACKERMAN, E. A - Where is a research frontier? Annals of the Assoc. Of American Geographers., vol. 53, n. 4, p.429-440, 1963.

AGNEW, C. e SPENCER, T. Editorial: Where have all the physical geographers gone? Transac Inst. of Brist. Geographers, NS, 24, p. 5-9, 1999.

ARENDT, H. A condição humana. Rio de Janeiro: Forense Universitária, 2001. 
BACHELARD, G. A formação do espírito científico. RJ: editora Contraponto, 1996.

BAKER, V.R. Geological fluvial geomorphology. Geological Society of America Bulletin, 100, p. 1157-67, 1988.

BAKER, V.R e TWIDALE, C.R. The reenchantment of geomorphology. Geomorphology, 4, p. 73-100, 1991.

BODMAN, A.R. Weavers of influence; the structure of contemporary geographic research. . Transc. Inst. Brit. Geogr. NS 16, 21-37, 2001.

BRAGA, M., GUERRA, A. e REIS, J.C. Breve história da ciência. RJ: Jorge Zahar editor, 4 vols, 2007-2008.

BROWN E.H. the content and relationships of physical geography. Geographical Journal, 141, p. 35-48, 1975.

BENJAMINN, Walter. Magia e técnica, arte e política. In; Obras escolhidas I, São Paulo: Brasiliense, 1985.

BOURDIEU, P. A economia das trocas simbólicas. SP: editora Perspectiva, 1992.

CASANOVA, P.G. As novas ciências e as humanidades. SP: Boitempo editorial, 2006.

COHEN, B e WESTFALL, R.S. (orgs) Newton: textos, antecedents $e$ comentários. RJ: ed. UERJ/Contraponto, 2002.

CHORLEY, R.J. The role and relations of physical geography. Progress in Geography, 3, p. 87-109, 1975.

CLIFFORD, N.J. The future of Geography: when the whole is less than the sum of its parts. Geoforum, 33, p. 431436, 2002.
Editorial: Physical geography - the naughty world revisited. . Transc. Inst. Brit. Geogr. NS 26, p. 387-389, 2001.

FOUCAULT, M. As palavras e as coisas: uma arqueologia das ciências humanas. SP: Martins Fontes, 1985.

GOUDIE, A.S. The integration of human and physical geography. Transc. Inst. Brit. Geogr. NS 11, p.454-8, 1986.

------., ATKINSON, B.W., GREGORY, K.J., SIMMONS, I.G., STODDART, D.R. e SUGDEN, D.A. (eds) The encyclopedic dictionary of physical geography. Oxford: Blackwell, 1994.

GREGORY, K.J., GURNELL, A.M. e PETTS, G.E. Restructuring physical geography. Transc. Inst. Brit. Geogr. NS 27 p. 136-154, 2002.

GOODCHILD, M.F. Geographical information science. International Journal of Geographical Information Systems., 61, p.31-45, 1992.

GUEROULT, M. Leibniz: dynamique et metaphisique. Paris: Aubier, 1967.

HARTSHORNE, R. Perspective on the nature of geography. Chicago: Rand McNally, 1959.

HAGGETT, P. Geography: a modern synthesis. London: Harper and Row, 1975.

HARVEY, D. Justice, Nature \& the Geography of Diference. NY, Blackwell, 1996.

Espacios del Capital. Madrid, Akal ediciones, 2007.

Teorias, Leyes y modelos en Geografia. Madrid: Alianza editorial, 1969. 
JOHNSTON, R.J. Four fixations and the quest for unity in geography. Transc. Inst. Brit. Geogr. NS 11, p.449-53, 1986.

----------. What Geography? What sustenance? Canadian Geographer, 38, p.309-13, 1994.

KEMP, K. e VCKOVSKI, A. Towards na ontology of fields in Proceedings of the Third International Conference on GeoComputation, 17-19 september 1998. Bristol, Reino Unido., 1998

KUEHN, M. Kant: a biography. Cambridge: Cambridge Univ. Press, 2001.

LANE, S. Constructive comments on D. Massey "Space-time, "Science"and the relationship between physical geography and human geography. Trans. Inst.Br. Geogr. NS, p.243-256, 2001..

LIVINGSTONE, D.N. The geographical tradition. NY, Blackwell, 1992.

LIVINGSTONE, D.N. Putting geography in its place. Australian Geographical Studies., 38, p. 1-9, 2000.

LUKÁCS, G. Ontologia do Ser Social. A falsa e a verdadeira ontologia de Hegel. SP: editora de Ciências Humanas, 1979.

MATOS, O. A Melancolia de Ulisses. IN: NOVAES, Adauto (coordenador). Os Sentidos da Paixão. SP: Companhia das Letras, 2002, p. 141-159.

MASSEY, D. Space-time, "science"and the relationship between physical geography and human geography. Transc. Inst. Brit. Geogr. NS 24, p. 261-276, 1999 2008.

RAPER, J e LIVINGSTONE, D.N. Let's get real: spatio-temporal identiy and geographic entities. Transc. Inst. Brit. Geogr. NS 26, p. 237-242, 2001.

ROSSI, P. Francis Bacon: da magia à ciência. Curitiba: UFPR/EDUEL, 2006.

RHOADS, B.L. Beyond pragmatism: the value of philosophical discourse for physical geography with emphasis on geomorphology. Annals Association of American Geographer., 89, 1999.

-------., e THORN, C.E. Contemporary philosophical perspectives on physical geography with emphasis on geomorphology. Geographical Review, 84, p. 90-101, 1994.

(eds.) The scientific

nature of geomorphology. Wiley, Chichester, 1996.

SCHAEFER, Fred. K. Exceptionalism in Geography: a metodological examination. An. Ass. Am. Geographers, XLIII, N. 3 , 1953, p.226-249.

THRIFT, N. The Future of geography. Geoforum 33, p. 291-298, 2002.

THRIFT, D.S. e WALLING, D. Geography in the United Kingdom 19962000. The Geographical Journal, 166, p.96-124, 2000.

VITTE, A.C. (org.) Contribuições à história e a epistemologia da Geografia. RJ; Bertrand Brasil, 2007.

--------. Influências da estética kantiana na gênese da geografia física. RJ: Anais do VII Encontro da ANPEGE, CD-ROOM, Niterói, UFF, 2007a.

WRIGLEY, N. e MATHEWS, S. Citation classics and citation levels in geography. Area, 18, p.185-94, 1986. 